\title{
Oxidation state of majoritic inclusions in diamond
}

\author{
Kiseeva E.S. ${ }^{1}$, Vasiukov D.M. ${ }^{2,3}$, Wood B.J. ${ }^{1}$, Stachel T. ${ }^{4}$, McCammon C.A. ${ }^{3}$, Chumakov \\ A. ${ }^{5}$, Harris J.W. ${ }^{6}$, Dubrovinsky L.S. ${ }^{3}$ \\ ${ }^{I}$ - Department of Earth Sciences, University of Oxford, UK, kate.kiseeva@earth.ox.ac.uk, \\ berniew@earth.ox.ac.uk \\ 2 -Laboratory of Crystallography, University of Bayreuth, Germany,vasyukov@physics.msu.ru \\ ${ }^{3}$-Bayerisches Geoinstitut, Universität Bayreuth, Germany, catherine.mccammon@uni-bayreuth.de, \\ Leonid.Dubrovinsky@uni-bayreuth.de \\ ${ }^{4}$ - Department of Earth and Atmospheric Sciences, University of Alberta, Canada, tstachel@ualberta.ca \\ 5 -ESRF-The European Synchrotron, Grenoble,France, chumakov@esrf.fr \\ ${ }^{6}$ - School of Geographical and Earth Sciences, University of Glasgow, UK, Jeff.Harris@glasgow.ac.uk
}

\section{Introduction}

Inclusions in diamond are the only currently known samples from the mantle transition zone and the lower mantle. Majoritic garnet is a rare inclusion (to date only 150-200 crystals have been reported), but its $\mathrm{Si}$ content is indicative of its depth of re-equilibration and it therefore has the potential to provide a depth profile of composition and properties such as oxidation state in the transition zone.

In this study, we use a novel technique - the Synchrotron Mössbauer Source (SMS) (beamline ID18 at ESRF) to determine the ferric-ferrous ratios of 13 small (30 to 100 micrometers in diameter) majoritic inclusions in diamonds from Jagersfontein. The inclusions were initially studied by X-ray diffraction at the Extreme Conditions Beamline (ECB), P02.2, at the PETRA III synchrotron, Hamburg and confirmed as predominantly monophase garnet single crystals or (in very few cases) as aggregates of single crystals. There is good agreement between determinations of $\mathrm{Fe}^{3+} / \mathrm{Fe}_{\text {tot }}$ using Mössbauer spectroscopy and single crystal X-ray refinement as well as calculations based on composition assuming stoichiometry.

\section{Results and discussion}

The major element compositions of studied inclusions are listed in Table 1.

\begin{tabular}{|c|c|c|c|c|c|c|c|c|c|c|c|c|c|c|}
\hline Sample & $\mathrm{SiO}_{2}$ & $\mathrm{TiO}_{2}$ & $\mathrm{Al}_{2} \mathrm{O}_{3}$ & $\mathrm{Cr}_{2} \mathrm{O}_{3}$ & $\mathrm{FeO}_{\text {tot }}$ & MnO & MgO & $\mathrm{CaO}$ & $\mathrm{Na}_{2} \mathrm{O}$ & $\mathrm{K}_{2} \mathrm{O}$ & $\mathbf{P}_{2} \mathbf{O}_{5}$ & Total & Pressure , GPa & $\mathrm{Fe}^{3+} / \mathbf{\Sigma} \mathrm{Fe}$ \\
\hline JF-01A & 42.67 & 0.13 & 19.95 & 0.24 & 12.58 & 0.42 & 17.51 & 6.14 & 0.15 & & 0.02 & 99.81 & 8.10 & $0.12(2)$ \\
\hline JF-09A & 42.38 & 0.09 & 21.03 & 0.08 & 14.08 & 0.40 & 16.19 & 6.11 & 0.20 & 0.01 & 0.02 & 100.59 & 7.88 & $0.11(3)$ \\
\hline JF-22A & 48.69 & 0.50 & 9.65 & 0.22 & 11.74 & 0.36 & 21.74 & 5.73 & 0.65 & 0.01 & 0.09 & 99.37 & 17.88 & $0.27(3)$ \\
\hline JF-37A & 42.46 & 0.17 & 20.64 & 0.14 & 12.95 & 0.38 & 16.88 & 6.46 & 0.14 & 0.01 & 0.02 & 100.24 & 7.74 & $0.08(5)$ \\
\hline JF-37B & 42.36 & 0.19 & 20.68 & 0.12 & 12.93 & 0.37 & 16.82 & 6.40 & 0.14 & 0.01 & 0.01 & 100.03 & 7.71 & $0.12(3)$ \\
\hline JF-39A & 45.20 & 0.31 & 15.01 & 0.24 & 10.76 & 0.24 & 20.29 & 5.67 & 0.37 & 0.01 & 0.03 & 98.13 & 13.47 & $0.20(1)$ \\
\hline$J F-42 A$ & 43.40 & 0.54 & 17.38 & 0.03 & 12.89 & 0.36 & 13.35 & 11.16 & 0.54 & 0.02 & 0.01 & 99.67 & 13.04 & $0.17(3)$ \\
\hline JF-44B & 44.12 & 0.32 & 17.87 & 0.31 & 11.75 & 0.30 & 17.73 & 7.97 & 0.18 & 0.01 & 0.02 & 100.58 & 10.15 & $0.15(3)$ \\
\hline JF-50A & 42.53 & 0.09 & 21.00 & 0.15 & 13.18 & 0.36 & 17.72 & 4.87 & 0.19 & 0.01 & 0.02 & 100.11 & 7.94 & $0.08(1)$ \\
\hline JF-55A & 47.94 & 0.41 & 11.91 & 0.34 & 9.44 & 0.25 & 21.99 & 7.41 & 0.43 & 0.02 & 0.02 & 100.15 & 15.56 & $0.30(3)$ \\
\hline JF-58A & 43.31 & 0.28 & 18.09 & 0.19 & 14.69 & 0.41 & 18.20 & 4.62 & 0.27 & 0.01 & 0.03 & 100.08 & 10.30 & $0.15(2)$ \\
\hline JF-58B & 43.67 & 0.28 & 18.41 & 0.17 & 14.63 & 0.40 & 18.42 & 4.62 & 0.26 & 0.01 & 0.03 & 100.90 & 9.92 & $0.27(5)$ \\
\hline JF-84A & 44.25 & 0.41 & 17.27 & 0.30 & 11.69 & 0.31 & 18.81 & 6.36 & 0.30 & 0.01 & 0.02 & 99.72 & 11.50 & $0.15(4)$ \\
\hline
\end{tabular}

Table 1. Major element compositions, pressure and ferric iron contents of analysed majoritic garnet inclusions (Tappert et al., 2005; Beyer and Frost, 2017).

The garnet inclusions we have studied are, in common with most other majorite inclusions, pyroxenitic in composition in that they follow the peridotite "trend" on a plot of $\mathrm{M}^{2+}$ versus $\left(\mathrm{M}^{4+}+\mathrm{M}^{5+}\right)$ (see Kiseeva et al., 2013 for details), but are low in $\mathrm{Cr}_{2} \mathrm{O}_{3}(0.03-0.34 \mathrm{wt} \%)$ and $\mathrm{Mg} \#(0.65-$ 0.81) and high in $\mathrm{CaO}(4.62-11.2 \mathrm{wt} \%)$ (Table 1, Fig. 1). 

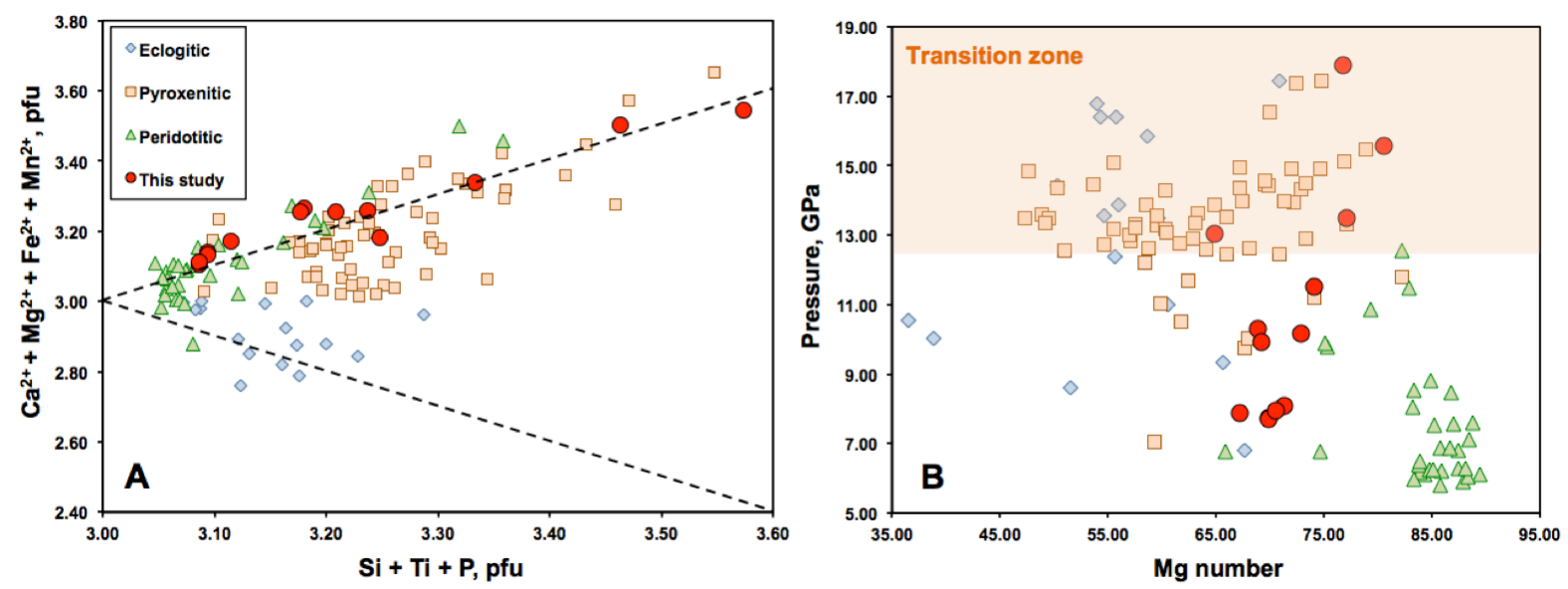

Figure 1. Majoritic garnet inclusions in diamonds worldwide (literature data from Kiseeva et al., 2013). Inclusions studied here from the Jagersfontein kimberlite are shown by red circles. In order to compare compositions with those of previous studies, all iron has been calculated as $\mathrm{Fe}^{2+}$. (A) Divalent cations plotted against Si, Ti and P. (B) Pressure according to Beyer and Frost (2017) geobarometer plotted against Mg number.

Our measurements show an increase in $\mathrm{Fe}^{3+} /\left(\mathrm{Fe}^{2+}+\mathrm{Fe}^{3+}\right)$ with increasing amount of majorite substitution and hence pressure (Fig. 2). Assuming the presence of pyroxene in the pyroxenitic diamond substrates, garnet compositions yield pressures of formation of 7.7-17.9 GPa using the Beyer and Frost majorite geobarometer (Beyer and Frost, 2017). These are minimum pressures, however, because equilibrium with pyroxene has not been demonstrated. Figure 2 shows that $\mathrm{Fe}^{3+} /\left(\mathrm{Fe}^{2+}+\mathrm{Fe}^{3+}\right)$ is extremely well correlated with calculated pressure, increasing from 0.08 at $7.7 \mathrm{GPa}$ to values between 0.30 at $16 \mathrm{GPa}$ and 0.27 at $18 \mathrm{GPa}$. Note that at least 4 of these 13 garnets were formed at (minimum) pressures of 13 to $18 \mathrm{GPa}$ and, therefore crystallised in the transition zone (410-660 km depth). It is also interesting to note that our measured $\mathrm{Fe}^{3+} /\left(\mathrm{Fe}^{2+}+\mathrm{Fe}^{3+}\right)$ values define a clear extension of the trend apparent in the data from peridotite xenoliths crystallised at lower pressures and that Fe from the transition zone garnets is at least twice as oxidised as in any garnet from xenoliths of subcratonic lithospheric mantle.

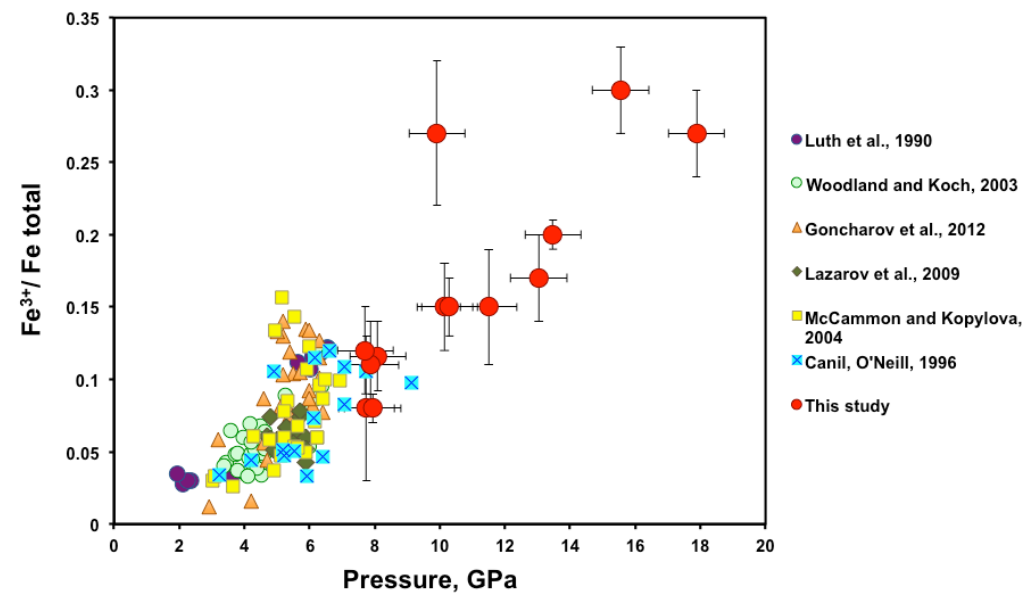

Figure 2. Ferric iron contents of majoritic garnets from Jagersfontein diamonds compared to lithospheric garnets from peridotite xenoliths. All ferric iron contents determined by Mössbauer spectroscopy. Data from Luth et al., 1990; Canil and O'Neill, 1996; Woodland and Koch, 2003; McCammon and Kopylova, 2004; Lazarov et al., 2009 and Goncharov et al., 2012.

The $\mathrm{Fe}^{3+} / \mathrm{Fe}^{2+}$ ratio of mantle minerals has been commonly used to determine the oxidation state of the mantle. According to experimental data and thermodynamic calculations, with increasing depth, $f \mathrm{O}_{2}$ should decrease at constant $\mathrm{Fe}^{3+} / \mathrm{Fe}^{2+}$ ratio (Wood et al., 1990), driving carbonate into the diamond 
stability field. Carbonate would therefore be unstable and should oxidise $\mathrm{Fe}^{2+}$ into $\mathrm{Fe}^{3+}$, with the latter dissolving into garnet according to reactions such as:

$$
4 \mathrm{Fe}_{2} \mathrm{SiO}_{4}+2 \mathrm{FeSiO}_{3}+\mathrm{CO}_{2}=2 \mathrm{Fe}_{3}^{2+}+2 \mathrm{Fe}_{2}{ }^{3+} \mathrm{Si}_{3} \mathrm{O}_{12}+\mathrm{C}
$$

This reaction implies that garnet in equilibrium with carbon (in the form of diamond) should have elevated $\mathrm{Fe}^{3+} / \mathrm{Fe}^{2+}$ ratios, consistent with our new observations. To our knowledge, these are the first data bearing on the oxidation state of majoritic garnets derived from the mantle transition zone.

Our results show that the mantle transition zone is highly heterogeneous and suggest that the diamond-forming process is intimately linked with the oxidation state of garnet according to reactions such as proposed above.

\section{References}

Beyer, C., Frost, D.J. (2017) The depth of sub-lithospheric diamond formation and the redistribution of carbon in the deep mantle. Earth and Planetary Science Letters, 461: 30-39.

Canil, D., ONeill, H.S.C. (1996) Distribution of ferric iron in some upper-mantle assemblages. Journal of Petrology, 37(3): 609-635.

Goncharov, A.G., Ionov, D.A., Doucet, L.S., Pokhilenko, L.N. (2012) Thermal state, oxygen fugacity and $\mathrm{C}-\mathrm{O}-\mathrm{H}$ fluid speciation in cratonic lithospheric mantle: New data on peridotite xenoliths from the Udachnaya kimberlite, Siberia. Earth and Planetary Science Letters, 357: 99-110.

Kiseeva, E.S. et al. (2013) Metapyroxenite in the mantle transition zone revealed from majorite inclusions in diamonds. Geology.

Lazarov, M., Woodland, A.B., Brey, G.P. (2009) Thermal state and redox conditions of the Kaapvaal mantle: A study of xenoliths from the Finsch mine, South Africa. Lithos, 112: 913-923.

Luth, R.W., Virgo, D., Boyd, F.R., Wood, B.J. (1990) Ferric iron in mantle-derived garnets implications for thermobarometry and for the oxidation state of the mantle. Contributions to Mineralogy and Petrology, 104(1): 56-72.

McCammon, C., Kopylova, M.G. (2004) A redox profile of the Slave mantle and oxygen fugacity control in the cratonic mantle. Contributions to Mineralogy and Petrology, 148(1): 55-68.

Tappert, R. et al. (2005) Diamonds from Jagersfontein (South Africa): messengers from the sublithospheric mantle. Contributions to Mineralogy and Petrology, 150(5): 505-522.

Wood, B.J., Bryndzia, L.T., Johnson, K.E. (1990) Mantle oxidation state and Its relationship to tectonic environment and fluid speciation. Science, 248(4953): 337-345.

Woodland, A.B., Koch, M. (2003) Variation in oxygen fugacity with depth in the upper mantle beneath the Kaapvaal craton, Southern Africa. Earth and Planetary Science Letters, 214(1-2): 295310 . 